\title{
The Assessment of Depression Level Among Diabetic Patients in Karachi Using BDI (Beck's Depression Inventory)
}

\author{
Kiran Rafiq ${ }^{1, *}$, Shagufta Nesar², Zafar Saied Saify³, Mohammad Azhar Mughal ${ }^{4}$, Alina Rizvi', Aleeza Raza ${ }^{1}$, \\ Alisha Hassan ${ }^{1}$ \\ ${ }^{1}$ Institute of Pharmaceutical Sciences, Jinnah Sindh Medical University, Karachi, Pakistan \\ 2Faculty of Pharmacy, Hamdard University, Karachi, Pakistan \\ ${ }^{3}$ International Center of Chemical \& Biological Sciences, HEJ, University of Karachi, Karachi, Pakistan \\ 4Department of Pharmacology, Jinnah Sindh Medical University, Karachi, Pakistan
}

\section{ABSTRACT}

\begin{abstract}
Background: Diabetes is co-morbid with various metabolic and psychological disorders. Diabetes and depression are both chronic
\end{abstract} conditions with allied adverse and complicated outcomes.

Objectives: The current study was designed and planned accordingly to elucidate the associated frequency of depression with DM (Diabetes Mellitus) type 2 and prescribing practice of doctors depending on the distressing reality and threatening figures.

Methodology: A prototype prospective study was monitored in different public and private sector hospitals and clinics of outpatient settings in Karachi after taking approval from the Ethical Review Board of Hamdard University. In this context, seven hundred patients having diabetes were covered in the study and their data were analyzed through the Statistical software version 20. Beck Depression Inventory (BDI) was the preferred approach to evaluate the depression level.

Results: The outcome of the study established the fact of high prevalence for the co-morbidity of stress, anxiety and depression among patients with diabetes in Karachi, specifically among age bracket from forty to sixty years. Unfortunately, $80 \%$ (544) of diabetic patients in the study were suffering from depression and anxiety, while only 22.05\% (120) patients were taking antidepressants and they were not counseled for the root cause of the disease. Severe depression (BDI score=38) was present in 100 subjects, moderate depression (BDI score $=27)$ in 200 subjects, and mild depression was present in 175 of subjects. Being a patient of DM is itself a strong reason for contracting a depressive disorder. The result highlight improper treatment of depression in diabetic patients.

Conclusion: However, the current situation demands to follow proper treatment through effective and appropriate drugs to treat the disease from progressing. Moreover, efforts should be undertaken to strengthen the healthcare system where practitioners, either doctors, pharmacists or nurses are liable for patient care in both the physical and psychological domains.

$\begin{array}{ll}\text { Keywords } & \text { *Address of Correspondence } \\ \text { Diabetes mellitus, Depression, BDI (Beck } & \text { kiranrafiq@hotmail.com } \\ \text { Depression Inventory), Outpatients. } & \end{array}$

Cite this article: Rafiq K, Nesar S, Saify ZS, Mughal MA, Rizvi A, Raza A, Hassan A. The Assessment of Depression Level among Diabetic Patients in Karachi Using BDI (Beck's Depression Inventory). RADS J Biol Res App/ Sci. 2019;10(2):109-113.

This is an Open Access article distributed under the terms of the Creative Commons Attribution License (http://creativecommons.org/licenses/by/4.0), which permits unrestricted use, distribution, and reproduction in any medium, provided the original work is properly cited.

\section{INTRODUCTION}

Depression is a ubiquitous condition that frequently and mostly co-exists with chronic conditions. The Diabetes Association of America and Diabetes Canada recommends the systematic study of depression in hyperglycemic patients to come up with roots cause of stress ${ }^{1,2}$. According to a report, approximately sixth part of 
the worlds' population is facing the continual consequences of diabetes that disrupt the metabolism of carbohydrates, lipids and proteins. The disease is considered as highly convoluted state that ultimately demands intensive self-care, (involving adaptability to the prescribed medications by the physician, along with timely monitoring of blood glucose), healthy and low carbohydrate diet, physical workout, preventive measures for foot care, regular screening for associated complications and follow-up visits to the consultant ${ }^{3-6}$. Preferably, a comprehensive therapy with a strong emphasis on addressing depression is required for optimal outcome ${ }^{7,8}$. For a decade, it has been a debatable question whether the monitoring of depression can be supportive to improve diabetes and its associated severity. Data obtained from different research studies sustain the reality, and importance of treating depression can be an indirect method to overcome the disease as depression itself is significantly responsible for reduced quality of life ${ }^{9,10}$. In primary care units, depression and diabetes are usually assessed as two commonly confronted clinical conditions. Approximately, $13 \%$ to $18 \%$ of people with diabetes mellitus are reported to have depression who visit clinical settings, and this combination could be bidirectional. Consequently, diabetes is more probably accountable for psychological conditions like depression or anxiety ${ }^{11-13}$. Although, the early stage of diabetes is mostly asymptomatic probably leading to longterm complications, various treatment regimens are required to maintain glucose and lipid levels along with blood pressure status of subjects. Feelings of anger, offense, destruction and social isolation are the factors highly accountable for intensifying the disease ${ }^{14-17}$. Consequently, co-morbidity of diabetes and stress threaten the lifespan rather than depression or diabetes alone and the condition is reported to have a prolonged duration of sickness and is sometimes associated with frequent hospitalization as compared to individuals having diabetes alone. Unfortunately, around $50 \%$ of patients remain undiagnosed and an even greater proportion cannot obtain management options of the disorder with reference to stress. Another study revealed frequent occurrence of depression in the diabetic group as compared to non-diabetics ${ }^{18-20}$. A bidirectional adverse interaction has been established through strong data between diabetes and depression ${ }^{21}$.

\section{MATERIALS AND METHODS}

\section{Sample Collection}

In the current study, a prototype prospective study was conducted in outpatient settings of the public and private sector hospitals and diabetic clinics in Karachi, Pakistan after seeking due permission. The duration of the study was from February to July 2018. Seven hundred $(n=700)$ diabetic patients who had been receiving various regimens of drugs were recruited in the study. Only 680 subjects agreed to join the survey. In the current study, the "Beck's Depression Inventory" was applied to examine the anxiety level of type 2 diabetic patients. The method adopted was a psychiatric measuring mechanism with expressive words and phrases with the relevancy of depression severity for a time period. The scale includes a total of 21 questions. Each question is given 0-3 points, and the total score is obtained with their addition. The entire gain ranges from 0 to 63 . The tool was found satisfactory for evaluating the depression level and for the purpose of the Beck Depression Inventory form was answered by the patients at the clinics ${ }^{22,23}$.

\section{Exclusion Criteria for the Study Population}

Patients having no will to participate, either male or female, were not recruited in the survey study. All females who were pregnant were also excluded from the present study. Hospitalized patients were also not included in the study.

\section{Data Assessment}

After collection of all information, the data were cleaned, coded and entered in SPSS version 20, through descriptive statistics consisting of percentages and frequency calculated. Depression levels of patients were evaluated through the BDI scale.

\section{RESULTS}

Out of 680 diabetic patients, $54.1 \%$ male and $45.9 \%$ were female. The result showed 41 to 60 years age group was more prone to diabetes (Table 1 and 2 ). 
Table 1. Frequency of Diabetes Occurrence According to Gender.

\begin{tabular}{cccc}
\hline S. No. & Gender & Frequency & $\%$ \\
\hline 1 & Male & 368 & 54.1 \\
\hline 2 & Female & 312 & 45.9 \\
\hline
\end{tabular}

Table 2. Frequencies of Diabetes Occurrence According to Age.

\begin{tabular}{cccc}
\hline S. No. & Age (Years) & Frequency & $\mathbf{( \% )}$ \\
\hline 1 & $1-20$ & 64 & 9.4 \\
\hline 2 & $21-40$ & 20 & 2.9 \\
\hline 3 & $41-60$ & 372 & 54.7 \\
\hline 4 & $61-80$ & 200 & 29.4 \\
\hline 5 & Above 80 & 24 & 3.5 \\
\hline 6 & Total & 680 & 100.0 \\
\hline
\end{tabular}

Among 680 diabetic patients, 544 suffered from depression and interestingly, physicians had not prescribed an antidepressant to all the patients having high level of depression with prominent symptoms, whereas only 120 patients received an antidepressant (Table 3). The current study was designed depending on the background and common social causes of diabetes and helped to establish depression as an important root cause of the disease. Gender distribution for the disease was observed slightly higher for males. During the study, a prescribing pattern for antidepressants was found to be followed by physicians which included Bromazepam, Alprazolam, Clomipramine and Escitalopram to some extent (Table 4). However, no practice of patient psychoanalysis was observed as the practice could help in declining anxiety but the present data show that the majority of population under the study was experientially untreated for depression (Table 3).

Table 3. Prescribing Frequencies of Antidepressants in Diabetic Patients.

\begin{tabular}{ccc} 
S. No. & $\begin{array}{c}\text { Prescribing Status of } \\
\text { Antidepressant }\end{array}$ & $\begin{array}{c}\text { Frequency } \\
(\%)\end{array}$ \\
\hline 1 & No & $424(77.94)$ \\
\hline 2 & Yes & $120(22.05)$ \\
\hline
\end{tabular}

Table 4. Commonly Prescribed Antidepressants to Diabetic Patients.

\begin{tabular}{ccc}
\hline S. No. & Medicine & Prescribing Percentage \\
\hline 1 & Bromazepam & 60 \\
\hline 2 & Alprazolam & 20 \\
\hline 3 & Clomipramine & 15 \\
\hline 4 & Escitalopram & 05 \\
\hline
\end{tabular}

Table 5. Level of Depression According to BDI in Diabetic Patients.

\begin{tabular}{cccc}
\hline S. No. & $\begin{array}{c}\text { Number of } \\
\text { Patients }\end{array}$ & $\begin{array}{c}\text { Total } \\
\text { Score }\end{array}$ & $\begin{array}{c}\text { Level of } \\
\text { Depression }\end{array}$ \\
\hline 1 & 175 & 14 & $\begin{array}{c}\text { Mild mood } \\
\text { disturbance }\end{array}$ \\
\hline 2 & 200 & 27 & $\begin{array}{c}\text { Moderate } \\
\text { depression }\end{array}$ \\
\hline 3 & 100 & 38 & $\begin{array}{c}\text { Severe } \\
\text { depression }\end{array}$ \\
\hline 4 & 69 & 49 & $\begin{array}{c}\text { Extreme } \\
\text { depression }\end{array}$ \\
\hline
\end{tabular}

The Beck Depression Inventory form ${ }^{22}$ was given to patients to fill out at the clinic. The activity result revealed that $544(80 \%)$ of diabetic patients suffered from depression that exhibited a very large number compared to the standard 24,25 . Interestingly, according to the results of a present study, the majority of the diabetic patients suffered from moderate depression $(B D I$ score $=27)$ and minimum number of patients fell in severe depression range $(\mathrm{BDI}$ score $=49)$ according to $\mathrm{BDI}$ scale calculation (Table 5).

\section{DISCUSSION}

The present study covers the prescribing pattern of drugs to treat diabetic complications and also its co-morbidity especially depression. The chances of diabetes alone were found in below frequency as compared to an association with depression. The research reveals that anxiety and depression are coupled with age and tend to peak in the forties and fifties. Then it drops after the age of sixty as anxiety issues are seen more common in the middle aged patients. Furthermore, other reasons for the 
development of anxiety are different socio-economic problems such as high expectations from employers, children and relatives in various scenarios along with social pressure mounting to a severity of the condition. The study reveals the correlation of life satisfaction with age and accordingly was found high before and after middle age.

During the current and various other studies on the correlation of hyperglycemic conditions and depression, self-care along with diabetes works significantly to prevent the upcoming multiple health consequences. Diet, exercise and glucose monitoring are the basic tools to fight the disease. However, monitoring anxiety and stress interestingly plays a vital role and influences the spectrum of diabetes. Physicians and pharmacists are highly accountable for analyzing the depressive symptoms in diabetics that should be addressed at the earliest either via counseling or through antidepressive medications. In preventive care; regular exercise, socialization, reading and other healthy activities keep the patient away from stress and its co morbidities ${ }^{26}$.

The collected data reveals that co-morbidity of depression with diabetes unfortunately remain unrecognized and untreated in two-thirds of patients approximately. In certain cases, both condition reach up to the chronic stage and severity, and such patients have no other choice than adding antidepressant medication to the regimen ${ }^{27-29}$. Moreover, prescribing practice must be focused on to individualize the antidepressant regimens for patients having diabetes. However, the practice should be carefully handled depending on the patience and restraint to support adaptability for diabetic patients as they are already sufferers of other complications and also burdened with extreme care regarding diet and lifestyle. Diabetes care associations suggest regular counseling to carefully address anxiety and stress among diabetics due to the prevalent association of depression with diabetes ${ }^{30}$.

\section{CONCLUSION}

The present data and outcome explicitly exhibit that the mental health co-morbidities are major consequences of risk for the deprived health status in diabetes, However, screening and monitoring of stress factors can be vital for reducing unavoidable health issues and psychological screening, especially for anxiety, that is significant for good health among patients with diabetes.

\section{LIST OF ABBREVIATIONS}

BDI Beck Depression Inventory

DM Diabetes Mellitus

\section{REFERENCES}

1. American Diabetes Association. Lifestyle Management: Standards of Medical Care in Diabetes. Diabetes Care. 2018; 41(1):S38-50.

2. Robinson DJ, Coons $M$, Haensel $H$, Vallis M, Yale JF. Diabetes and mental health. Can J Diabetes. 2018; 42(1):S130-41.

3. Russel LB, Suh DC, Safford MA. Time requirements for diabetes self-management: too much for many? J Fam Pract. 2005; 54(1):52-6.

4. Lustman PJ, Clouse RE. Treatment of depression in diabetes: Impact on mood and medical outcome. J Psychosom Res. 2002; 53(4):917-24.

5. Egede LE, Nietert PJ, Zheng D. Depression and allcause and coronary heart disease mortality among adults with and without diabetes. Diabetes Care. 2005; 28(6):1339-45.

6. Black SA. Increased health burden associated with comorbid depression in older diabetic Mexican Americans. Results from the Hispanic Established Population for the Epidemiologic Study of the Elderly survey. Diabetes care. 1999; 22(1):56-64.

7. Bryan C, Songer T, Brooks MM, Rush AJ, Thase ME, Gaynes B, et al. The impact of diabetes on depression treatment outcomes. General Hospital Psychiatry. 2010; 32(1):33-41.

8. Ali S, Stone MA, Peters JL, Davies MJ, Khunti K. The prevalence of co-morbid depression in adults with Type 2 diabetes: A systematic review and meta-analysis. Diabet Med. 2006; 23(11):1165-73.

9. Barnard KD, Skinner TC, Peveler R. The prevalence of co-morbid depression in adults with Type 1 diabetes: Systematic literature review. Diabet Med. 2006; 23(4):445-8.

10. Pan $A$, Lucas $M$, Sun $Q$, van Dam RM, Franco $\mathrm{OH}$, Manson JE, et al. Bidirectional association between depression and type 2 diabetes mellitus in women. Arch Intern Med. 2010; 170(21):1884-91.

11. Ciechanowski PS, Katon WJ, Russo JE. Depression and diabetes: Impact of depressive symptoms on adherence, function, and costs. Arch Intern Med. 2000; 160(21):3278-85.

12. Gazmararian JA, Ziemer DC, Barnes C. Perception of barriers to self-care management among diabetic patients. Diabetes Educ. 2009; 35(5):778-88. 
13. Ali S, Stone M, Skinner TC, Robertson N, Davies M, Khunti K. The association between depression and health-related quality of life in people with type 2 diabetes: A systematic literature review. Diabetes Metab Res Rev. 2010; 26(2):75-89.

14. Goldney RD, Phillips PJ, Fisher LJ, Wilson DH. Diabetes, depression and quality of life: A population study. Diabetes Care. 2004; 27(5):1066-70.

15. Jacobson AM, Groot M, Samson JA. The effects of psychiatric disorders and symptoms on quality of life in patients with type I and type II diabetes mellitus. Qual Life Res. 1997; 6(1):11-20.

16. Vamos EP, Mucsi I, Keszei A, Kopp MS, Novak M. Comorbid depression is associated with increased healthcare utilization and lost productivity in persons with diabetes: A large nationally representative Hungarian population survey. Psychosom Med. 2009; 71(5):501-7.

17. Katon WJ, Simon G, Russo J, Von Korff M, Lin EH, Ludman E, et al. Quality of depression care in a population-based sample of patients with diabetes and major depression. Medical Care. 2004; 24(12):1222-9.

18. Li C, Ford ES, Zhao G, Ahluwalia IB, Pearson WS, Mokdad $\mathrm{AH}$. Prevalence and correlates of undiagnosed depression among US adults with diabetes: The Behavioral Risk Factor Surveillance System, 2006. Diabetes Res Clin Pract. 2009; 83(2):268-79.

19. Anderson RJ, Freedland KE, Clouse RE, Lustman PJ. The prevalence of comorbid depression in adults with diabetes: A meta-analysis. Diabetes Care. 2001; 24(6):1069-78.

20. Sun N, Lou P, Shang Y, Zhang P, Wang J, Chang G, et al. Prevalence and determinants of depressive and anxiety symptoms in adults with type 2 diabetes in China: A cross-sectional study. BMJ Open. 2016; 6(8):e012540.
21. Golden SH, Lazo M, Carnethon M, Bertoni AG, Schreiner PJ, Roux AV, et al. Examining a bidirectional association between depressive symptoms and diabetes. Jama. 2008; 299(23):27519.

22. Beck AT, Ward CH, Mendelson M, Mock J, Erbaugh J. An inventory for measuring depression. Arch Gen Psychiatry. 1961; 4(6):561-71.

23. Pouwer F, Geelhoed-Duijvestijn PH, Tack CJ, Bazelmans E, Beekman AJ, Heine RJ, et al. Prevalence of comorbid depression is high in out-patients with Type 1 or Type 2 diabetes mellitus. Results from three out-patient clinics in the Netherlands. Diabet Med. 2010; 27(2):217-24.

24. Sweileh WM, Abu-Hadeed HM, Al-Jabi SW, Sa'ed $\mathrm{HZ}$. Prevalence of depression among people with type 2 diabetes mellitus: a cross sectional study in Palestine. BMC Public Health. 2014; 14(1):2-11.

25. Lin EH, Katon W, Von Korff M, Rutter C, Simon GE, Oliver $\mathrm{M}$, et al. Relationship of depression and diabetes self-care, medication adherence, and preventive care. Diabetes Care. 2004; 27(9):2154-60.

26. Wayne J. Katon. The Comorbidity of Diabetes Mellitus and Depression. The American Journal of Medicine. 2008; 121:S8-15.

27. Katon W, Cantrell CR, Sokol MC, Chiao E, Gdovin JM. Impact of antidepressant drug adherence on comorbid medication use and resource utilization. Arch Intern Med. 2005; 165(21):2497-503.

28. American Diabetes Association. Standards of medical care in diabetes. Diabetes Care. 2007; 30(1):S4-41.

29. Lustman PJ, Clouse RE. Depression in diabetic patients: The relationship between mood and glycemic control. J Diabetes Complicat. 2005; 19(2):113-22.

30. Park $H$, Hong $Y$, Lee $H, H a ~ E$, Sung $Y$. Individuals with type 2 diabetes and depressive symptoms exhibited lower adherence with self-care. J Clin Epidemiol. 2004; 57(9):978-84. 